\title{
CONFERENCE ON INDUSTRIAL RADIOLOGY
}

$\mathrm{O}^{\mathrm{x}}$ September 24 the Industrial Radiology Group of the Institute of Physics held the first meeting since its inauguration, this taking the form of an afternoon conference at the Royal Institution, presided over by Prof. J. A. Crowther. The Conference was opened by Sir William Bragg who first spoke of the early days of X-rays, almost fifty years ago, before commenting on the many industrial uses to which the radiations are now put. He welcorned the formation of a group of workers interested in radiology and hoped it will be a success in sharing experience and knowledge and also in stimulating further interest in the subject.

Three papers were read before the conference, forming the basis for the following discussion. The first of these, given by Dr. W. Betteridge, and entitled "The Application of X-Rays to Industrial Problems", was a general review of the subject. The physical properties of X-rays important in radiology were briefly described, and led to a consideration of the factors involved in the production of a radiograph. The points to be considered in the choice of the different variables such as tube voltage, tube to film distance, etc., were considered, and the importance of blocking off, the use of filters, intensifying screens and diaphragms were briefly described.

Various fields in which radiology has proved of service were then enumerated-the examination of castings and welded joints was mentioned but left for the following speakers to treat in more detail, and the miscellaneous uses of the rays were then described under grouped headings. The examination of assembled structures was considered to be the most important use after the two already mentioned, these being examined for the presence and correct alignment of component parts. Radio valves, small ammunition, shell fuses, electric heater elements, sparking plugs, etc., were mentioned as examples and slides shown illustrating the types of defect looked for. Such examinations are frequently carried out by fluoroscopic means. The routine examination of food products, fire bricks, are carbons, etc., was also mentioned, and stereoradiography for the location of defects and the measurement of wall thickness was described. The observation of objects in a furnace was illustrated among uses in a research laboratory, and microradiography was dealt with. This latter consists of the radiography of a very thin metal sample on fine-grain film with soft radiation, subsequent optical magnification of the radiograph giving the equivalent of a photomicrograph, and showing the presence of different phases by the different degrees of absorption; it was described as of particular value in the study of coring and segregation in a solid solution. The use of $\gamma$-rays in the examination of thick sections of heavy metals was mentioned.

A final section of Dr. Betteridge's paper dealt very briefly with the application of X-ray diffraction methods to industrial problems, reference being made to the recent symposium published in the Journal of Scientific Instruments. The Debye-Scherrer powder photograph was used to illustrate the different types of problem which could be dealt with, determination of the crystal structure, or its comparison with standards, being described for the identification of unknown materials in very small quantities, and the use of accurate parameter measurements for the analysis of alloys in solid solution and the measurement of elastic stresses was also mentioned. How the appearance of the diffracted lines could be used to yield information as to grain size, state of cold work or preferred orientation, and. for the study of relaxation and recrystallization formed the closing section of the paper.

The next paper, by J. J. Gillespie, dealt with "The Applications of Radiography in the Inspection and Control of Welds". After a short description of the practice of welding and the bodies to which it is frequently applied, Mr. Gillespie dealt more fully with the methods used in the examination of welded joints in boilers and other pressure vessels. The need for careful preparation of the weld before examination. was emphasized, in order that surface defects should not mask the internal faults for which search was being made ; and it was pointed out that the marking out of the body before radiography should be systematically and permanently done, so that at any future date the radiograph of a particular section could be located. Dark-room technique must be maintained at a high standard since an otherwise perfect radiograph can easily be spoiled by faulty processing. The common types of defect were then enumerated, the chief classes being porosity, slag inclusions, lack of penetration and cracks, and slides were shown to illustrate the different degrees and forms in which these faults could occur. It was stated that a certain amount of uniformly distributed porosity or slag inclusions can be tolerated in a weld, particularly if the metal is of fairly thick section, but lack of penetration and cracks are more serious defects likely to result in stress concentration, and a high standard of acceptance has to be maintained. Mr. Gillespie stated that a generally agreed standard of acceptance is becoming a necessity.

The third paper, on the "Application of X-Rays to the Examination of Magnesium Alloy Castings", was contributed by P. M. Bailey. It was first stated that fluorescent screen inspection of magnesium castings is unsatisfactory, as it is, in general, quite impossible to detect microshrinkage, the characteristic fault of these alloys, and the minimum size of fault detectable is about seven times as great as that shown on a radiograph. The type of X-ray film found most suitable for this work has a fine grain, and the highest contrast is not found desirable; for this reason filters with an absorption up to 50 per cent of that in the easting itself are frequently used, although in general, filters are unnecessary for magnesium. Emphasis was laid on the use of a suitable viewing lantern, and modifications to commercial lanterns found necessary, such as the addition of blinds for reducing the area illuminated and the introduction of high-power lamps, were described.

Typical defects of magnesium castings were described, microshrinkage, which can reduce the tensile strength of the material from about ten to five tons per square inch, being paramount. The incidence of blow-holes and dross inclusions, both often due to faulty foundry technique, was mentioned, and it was pointed out that cracks, which, in the case of die castings, are 
usually due to poor dies, can easily be missed if the direction of the X-ray beam lies far from the plane of the crack. The necessity of close collaboration between radiologist and foundry manager was emphasized, and the procedure followed by $\mathrm{Mr}$. Bailey himself was described. The breaking-up of castings in order to confirm and supplement radiographic inspection is essential, especially for the detection of microshrinkage; this is helped by heattreating the castings before breaking, the oxidation resulting making the microshrinkage more readily visible.

A lengthy discussion followed these papers and was contributed to by many speakers. Practical details, both difficulties which have been encountered and hints to overcome them, were mentioned, among the latter being the use of rubber cassettes which can be evacuated to hold intensifying screens in close contact with the film, the advantage of these being their flexibility, enabling them to be adjusted to close contact with irregularly shaped bodies; and the use of mercury for blocking off holes in an other- wise uniform plate. The most important point raised during the discussion, however, was the need for standardization of the acceptable limit for given types of fault. It was generally agreed that standards for welds would not be too difficult to formulate, particularly since welds are usually in material of uniform section and regular shape, but it would be much less easy to arrive at similar standards for castings. The responsibility for the determination of standards was discussed and there was agreement that the final decision should rest with the designer of a component, the function of the radiologist being to interpret the radiographs to the designer.

It was decided that the Radiology Group of the Institute of Physics is not in a position to undertake the preparation of radiographic standards, but Dr. L. Mullins, the secretary of the Group, pointed out that standardization is very necessary in other fields, and hopes, for example, that the Group will be able to put forward suggestions which will result in a reduction of the many different types and sizes of camera used in X-ray diffraction work.

\section{TECHNICAL ABILITY AND THE WAR EFFORT}

\begin{abstract}
A PRIME necessity in a war-time economy is for the maximum and most efficient use of all the country's resources. Particularly necessary in this War is the full use of technical-man-power. After two years of war, when it is implied by Government spokesmen that we still lack sufficient material to contemplate an offensive against the enemy, it is disquieting to learn that there still exists a widespread misuse of technical man-power.

At a national conference for members in engineering and aircraft industries, held at Birmingham on September 7 under the auspices of the Association of Scientific Workers, delegates stated that many industrial scientists and technicians are still working on peace-time problems. Others with insufficient work to do are being kept together as teams and find the Essential Work Order used to prevent release from their present firms and the transfer of their ability elsewhere. Delegates made it clear that this situation has arisen from the concern of some industrial firms with the problems of post-war competition. Speakers criticized the absence of any proper pooling of information. They spoke of production being held up while technicians completed designs or solved problems already dealt with by a parallel organization, and of the withholding of full technical information from designers of apparatus.

There was criticism of the scientific ability of some persons at present in charge of technical staff. A delegate from the aircraft industry spoke of technical leadership being in the hands of former racing drivers.

Many speakers felt that the combination of inefficient management, the concern of firms for private interests, the scheduling of overtime as a pretence of activity when there is insufficient work to do and similar experiences have given rise to a general apathy regarding production and that it is necessary for this to be broken down by close co-operation between marıgement and employees.
\end{abstract}

The remainder of the conference dealt with working conditions in these industries. Cases were put forward of qualified men receiving less remuneration than workmen under their supervision. Strong exception was taken to the system whereby university graduates rated as student apprentices are put on to ordinary production work at nominal salaries. Speakers clearly felt that little improvement in the status of scientific workers would be effected unless the Association of Scientific Workers could establish a minimum salary scale for all grades of scientific and technical staff.

The Conference therefore passed the following resolutions :

(1) All technical staffs not fully engaged on the war effort or engaged on development in preparation for post-war competition should be transferred to other departments.

(2) Real pooling of technical information and facilities should take place between firms producing similar articles, and between Government depart. ments and firms producing for them.

(3) All scientific and technical work should be under the direction only of persons with adequate technical experience and qualifications.

(4) There should be genuine co-operation between managers and workpeople to secure greater enthusiasm for the war effort.

(5) An attitude of vigilance should be adopted regarding the working of the Essential Work Order, so that it shall not be allowed

(a) to hinder the war effort by permitting managements to retain staff when their transfer would be in the national interest;

(b) to serve as an instrument of victimization of active trade unionists.

To carry this programme into effect the Conferenee proposed several points of action for the consideration of nembers of the Association, full details of which can be obtained from the Association of Scientific Workers, 30 Bedford Row, London, W.C.1. 